\title{
Analisis Pemanfaatan Sistem Informasi Manajemen Rumah Sakit (SIMRS) Pada RRSUD DOK II Jayapura
}

\author{
Ruth Molly ${ }^{1}$, Meyrolen Itaar ${ }^{2}$ \\ 1,2Information System, Fakultas Teknologi Informasi, Satya Wacana Christian University, \\ Indonesia \\ Email: 1682017129@student.uksw.edu,2meyrit08135412@gmail.com
}

\begin{abstract}
Abstrak
Perkembangan dan Kemajuan teknologi informasi saat ini sudah sangat luas. Bagi suatu instansi/ perusahaan informasi yang digunakan sebagai basis administrasi dan pengolahan data merupakan sistem aplikasi di berbagai bidang yang diharuskan menggunak sistem informasi itu. Sistem informasi rumah sakit memiliki peranan penting dalam pelayanan klinis dan administratif. Rumah sakit yang menggunakan sistem berbasis elektronik (SIMRS) itu dirancang untuk mengintegrasi fungsi utama rumah sakit ke dalam satu sistem terpadu yang disimpan dalam pusat database.
\end{abstract}

Keywords: Sistem Informasi, SIM, Implementasi SIMRS

\section{PENDAHULUAN}

Rumah sakit merupakan salah satu sarana pelayanan kesehatan yang sangat di butuh kan bagi semua orang. Kualitas pengelolahan informasi merupakan faktor penting bagi keberhasilan institusi pelayanan kesehatan, maka dari itu Teknologi informasi memiliki peran penting dalam pelayanan kesehatan saat ini. Sistem informasi mempunyai 3 peranan penting dalam mendukung proses pelayanan kesehatan, yaitu: mendukung proses dan operasi pelayanan kesehatan, mendukung pengambilan keputusan staf dan manajamen serta mendukung berbagai strategi untuk keunggulan kompetitif. Sistem informasi rumah sakit (SIMRS) yang digunakan di sebuah rumah sakit harus memberikan kemudahan dalam operasional serta harus dapat mengatasi kendala pelayanan pasien yang ada di rumah sakit tersebut . 


\section{Journal of Software Engineering Ampera}

Vol. 2, No. 2, June 2021 e-ISSN: 2775-2488

https://journal-computing.org/index.php/journal-sea/index

Rumah sakit yang memiliki setiap sistem informasi harus menyediakan akses informasi yang tepat waktu, dan pasti akan mendapatkan tekanan agar dapat memperbaiki pelayanan medis, mengurangi kesalahan medis, dan pada saat yang sama harus bisa memonitor aktifitas pelayanan serta mengendalikan biaya operasional. Maka dari itu rumah sakit harus memiliki SIM (Sistem Informasi Manajemen ) yang dapat mengintegrasi dan yang bisa sharing informasi real-time, tepat dan akurat. Sistem informasi manajemen ini tidak bisa berjalan secara otomatis apabila tidak didukung sistem perangkat lunak ( software system ) atau sistem enterprise ( enterprise software ) yang sudah tertanam dalam server rumah sakit tersebut. Sistem informasi rumah sakit (SIMRS) dapat dicirikan dengan fungsinya melalui informasi dan jenis layanan yang ditawarkan. Sistem informasi merupakan suatu sistem yang fungsi internalnya terbatas pada pemrosesan informasi dengan melakukan 6 tipe operasi, antara lain menangkap (capturing), mentransmisikan (transmitting), menyimpan (storing), mengambil (retrieving), memanipulasi (manipulating), dan menampilkan (displaying) informasi.

Untuk mendukung perawatan pasien dan administrasinya, SIMRS mendukung penyediaan informasi, terutama tentang pasien, dalam cara yang benar, relevan dan terbarukan, mudah diakses oleh orang yang tepat pada tempat/lokasi yang berbeda dan dalam format yang dapat digunakan. Transaksi data pelayanan dikumpulkan, disimpan, diproses, dan didokumentasikan untuk menghasilkan informasi tentang kualitas perawatan pasien dan tentang kinerja rumah sakit serta biaya. Ini mengisyaratkan bahwa sistem informasi rumah sakit harus mampu mengkomunikasikan data berkualitas tinggi antara berbagai unit di rumah sakit. Selain komunikasi, tujuan penting lain dari SIMRS adalah pertukaran data elektronik antar penyedia layanan kesehatan (dokter praktik, fasilitas primer dan rumah sakit) sehingga dapat menjamin ketersediaan informasi pasien secara komprehensif dan efisiensi pelayanan.

Sistem Informasi Manajemen Rumah Sakit (SIMRS) adalah sebuah sistem informasi yang terintegrasi yang disiapkan untuk menangani keseluruhan proses manajemen rumah sakit, mulai dari pelayanan diagnosa dan tindakan untuk pasien, medical record, apotek, gudang farmasi, penagihan, database personalia, penggajian karyawan, proses akuntansi sampai dengan pengendalian oleh manajemen. 


\section{Journal of Software Engineering Ampera}

Vol. 2, No. 2, June 2021 e-ISSN: 2775-2488

https://journal-computing.org/index.php/journal-sea/index

Penggunaan SIMRS di rumah sakit dapat mengatasi hambatan-hambatan dalam pelayanan kesehatan di rumah Sakit, keberadaan SIMRS sangat dibutuhkan, sebagai salah satu strategi manajemen dalam meningkatkan mutu pelayanan kesehatan dan memenangkan persaingan bisnis. Sistem informasi manajemen merupakan prosedur pemprosesan data berdasarkan teknologi informasi yang terintegrasi dan diintergrasikan dengan prosedur manual dan prosedur yang lain untuk menghasilkan informasi yang tepat waktu dan efektif untuk mendukung proses pengambilan keputusan manajemen.

Berdasarkan uraian dari latar belakang di atas, maka rumusan masalah pada penelitian ini yaitu (1) Bagaimana pengaruh penerapan SIM RS terhadap efisien kinerja karyawan ?. (2) Bagaimana Perkembangan SIM RS dalam pelayanan kesehatan pada RSUD Jayapura ?. (3) Bagaimana efektifitas pengelolaan SIM RS dalam pelayanan kesehatan pada RSUD Jayapura ?. (4) Berapa besar peranan SIM RS dalam pelayanan kesehatan pada RSUD Jayapura ?. (5) Bagaimana ketersedian informasi terkait dengan proses pelaksanaan SIM RS di RSUD DOK II Jayapura?.

\section{METODOLOGI PENELITIAN}

\subsection{Metode Penelitian}

Proses penelitian diawali dengan studi pustaka terhadap sejumlah referensi yang berkaitan dengan topik penelitian ini, terutama untuk memperoleh pengetahuan dan informasi terkini yang berkaitan dengan SIMRS. Studi lapangan (ground research) dilakukan untuk mengumpulkan data dan dokumen mengenai luas ruang bangunan rumah sakit dan struktur organisasi yang ada. Jenis penelitian ini merupakan penelitian kuantitatif dengan metode penelitian deskriptif yaitu menemukan gambaran yang lebih dalam tentang pemanfaatan sistem informasi manajemen rumah sakit (SIMRS) di RSUD DOK II Jayapura. Pengumpulan data dengan menggunakan teknik pengumpulan data Wawancara mendalam (in-depth interviews) yaitu melakukan wawancara yang sudah termasuk dalam kategori yang di rekam meggunakan rekaman di handphone atau tape recorder karena dalam pelaksanaanya lebih bebas bula dibandingkan dengan wawancara terstruktur. Penelitian ini terbagi ke dalam 3 langkah sebagai berikut: 
Journal of Software Engineering Ampera

Vol. 2, No. 2, June 2021 e-ISSN: 2775-2488

https://journal-computing.org/index.php/journal-sea/index

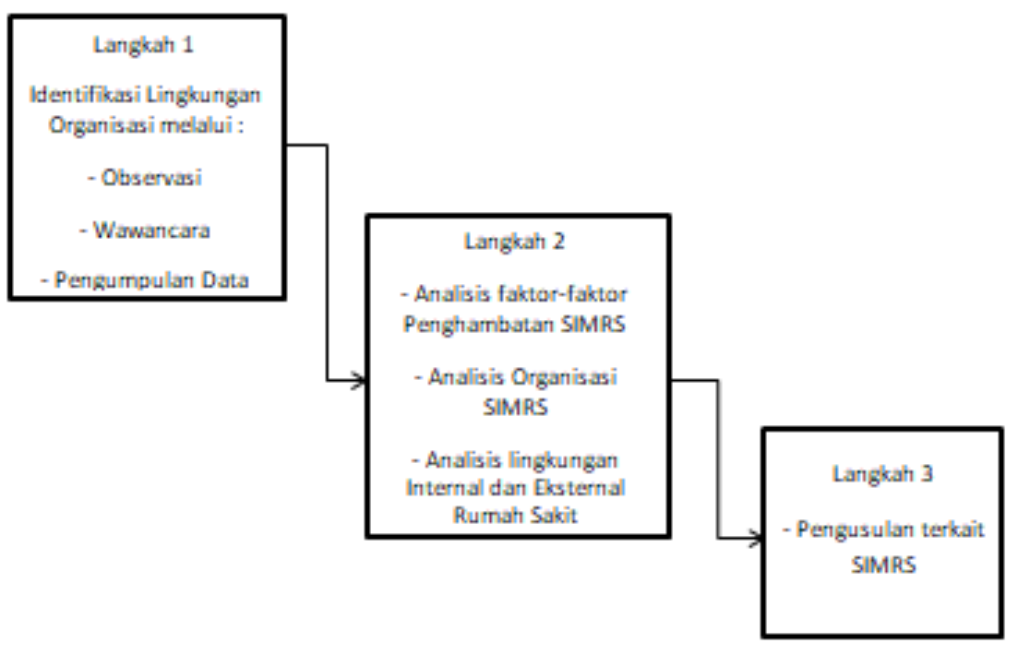

Gambar 1. Kerangka Penilitian SIMRS

1) Identifikasi Lingkungan Organisasi melalui, Observasi, wawancara, dan pengumpulan data.

2) Menganalisis Faktor-faktor Penghambat SIMRS, Organisasi SIMRS, dan Lingkungan Internal dan Eksternal Rumah Sakit.

3) Pengusulan terkait SIMRS.

\section{HASIL DAN PEMBAHASAN}

\subsection{Analis Data Penelitian}

Metode pengumpulan data dariinforman menggunakan metode Wawancar mendalam (Indepth interview). Setelah mendapatkan izin, peneliti mengunjungi informan pada ruang instalasi SIMRS serta memulai perkenalan dan memberikan penjelasan mengenai tujuan dari kunjungan penelitian. Kegiatan wawancara mendalam dilakukan di ruang Instalasi TI/ SI. Waktu wawancara disesuaikan dengan waktu luang yang diberikan informan.

\subsection{Tentang Kualitas SIMRS}

Berdasarkan hasil wawancara dan meneliti dapat disimpulkan bahwa, SIMRS di RSUD Dok II Jayapura belum dijalankan dengan baik. Bisa dilihat dari faktorfaktor penghambatnya seperti Faktor Human, Organization dan Technology. 


\section{Journal of Software Engineering Ampera}

Vol. 2, No. 2, June 2021 e-ISSN: 2775-2488

https://journal-computing.org/index.php/journal-sea/index

\subsubsection{Faktor Human}

Komponen yang terdiri dari manusia yang bertanggung jawab atas terselenggaranya proses SIM di Rumah Sakit, seperti pimpinan RS/Manajer dan para pegawai RS yang berhubungan dengan sistem komputer yang terkait satu sama lain. Human adalah efek dan fungsi pertama dalam penggunaan SIMRS, Human sangat dibutuhkan dalam pengelolahan SIMRS di Rumah Sakit. Terkadang efek dari Human bisa menghambat berjalannya SIMRS karena, manusia yang mengerjakan, manusia yang mengelolah, manusia yang mengimplementasikan dan manusia yang memelihara SIMRS itu sendiri.

\subsubsection{Faktor Organization}

Hasil dari wawancara yang mendalam (indepth interview) menceritakan tentang manajemen RSUD yang berubah yang juga menjadi efek berjalannya SIMRS di rumah sakit tersebut. Pada Tahun 2006 sampai dengan 2007 SIMRS di RSUD Dok II Jayapura sudah dijalankan dan berjalan dengan baik, tetapi terjadi pergantian pada manajemen rumah sakit yang dimana semua diperbaharui lagi atau di gantikan dengan sistem baru menurut manajemen tersebut. Para organisasi atau staff IT yang dulu mengelolah SIMRS tersebut telah di gantikan dengan organisasi baru yang mengelolah SIMRS tersebut yang dimana, menurut saya belum semuanya mengerti tentang pengelolahan SIMRS di rumah sakit melalui penilaian wawancar pada staff baru di ruangan instalasi IT/SI. SIMRS pada rumah sakit Dok II Jayapura masih dalam proses pengembangan bertahap dan belum bisa dijalankan dengan baik.

\subsubsection{Faktor Technology}

Fasilitas penunjang SIMRS yang disiapkan RSUD Jayapura untuk tahap 1 SIMRS sudah siap. Tahap 1 yang dimaksud mengenai pendaftaran dan poliklinik. RSUD sudah siapkan fasilitas yang sudah lengkap mulai dari pc dan ketersediaan jaringan. Salah satu aplikasi yang disusun sedemikian rupa untuk dipakai RSUD yaitu D'HEALTH, yang hampir mirip dengan rekam medik tetapi aplikasi ini masih belum bisa di jalankan dikarenakan bertabrakan dengan rekam medik jadi, rumah sakit masih menunggu program selanjutnya. Rekam medik pada RSUD masih ada kendala dalam penginputan dengan nomor rekam medik yang belum sesuai. Pada proses penyimpanan semua data pada RSUD belum semuanya online karena, terjadi kendala pada data pasien yang input. 


\section{Journal of Software Engineering Ampera}

Vol. 2, No. 2, June 2021 e-ISSN: 2775-2488

https://journal-computing.org/index.php/journal-sea/index

Dengan penelitian ini dapat disimpulkan bahwa di RSUD Dok II Jayapura pada penggunaan SIMRS belum sepenuhnya digunakan di rumah sakit. Selain itu penelitian ini juga menyatakan bahwa dalam menjalankan SIMRS perlunya SOP, supaya setiap kinerja dapat terkendali dengan baik, sebagai acuan dalam pelaksanaan kegiatan tertentu bagi semua pekerja, dan supervisor, untuk menghindari kegagalan atau kesalahan (dengan demikian menghindari dan mengurangi konflik), keraguan, duplikasi serta pemborosan dalam proses pelaksanaan kegiatan, parameter untuk menilai mutu pelayanan,menjamin penggunaan tenaga dan sumber daya secara efisien dan efektif, menjelaskan alur tugas, wewenang dan tanggung jawab dari petugas yang terkait dan sebagai dokumen yang akan menjelaskan dan menilai pelaksanaan proses kerja bila terjadi suatu kesalahan atau dugaan mal praktek dan kesalahan administratif laiinnya, sehingga sifatnya melindungi rumah sakit dan petugas.

Menurut pendapat peneliti, dengan adanya SOP ini terdapat kegiatan proses pengolahan SIMRS sesuai dengan target kinerja performa dan pembuatan SOP mampu melengkapi dan mengembangkan SIMRS sesuai tujuan sehingga SIMRS dapat digunakan sepenuhnya. Untuk dapat mempercepat pelayanan dapat terkoneksi maka, dibutuhkan kebutuhan teknologi yang lengkap seperti wifi dan jaringan.

\section{KESIMPULAN}

Berdasarkan hasil penelitian tentang Analisis Pemanfaatan Sistem Informasi

Manajemen Rumah Sakit di RSUD Dok II Jayapura, maka dapat diperoleh beberapa kesimpulan sebagai berikut :

1. Kualitas SIMRS yang didapatkan bahwa informan mengatakan bahwa perubahan pada manajemen rumah sakit menjadi salah satu penghambat dalam mengembangkan SIMRS pada Rumah Sakit. Permasalahan pada SIMRS salah satunya adanya penghambat pada server dan ketidaksesuian aplikasi. Hal ini seharusnya pihak terkait lebih meningkatkan kepedulian terhadap SIMRS.

2. Kualitas SIMRS ditinjau dari SDM didaptkan bahwa informan mengantakan bahwa jumlah SDM memadai kecuali programmer, tidak ada pengadaan pelatihan rutin untuk meningkatkan kompetensi SDM, ketidakdisiplinan petugas, tidak adanya reward dan punisment. 


\section{Journal of Software Engineering Ampera}

Vol. 2, No. 2, June 2021 e-ISSN: 2775-2488

https://journal-computing.org/index.php/journal-sea/index

Seharusnya pihak terkait lebih meningkatkan kepedulian terhadap SDM SIMRS. Jika SDM SIMRS khususnya programmer kurang, maka rumah sakit busa melakukan pengrekrutan sesuai dengan kebutuhan dan kualifikasi pendidikan.

\section{DAFTAR PUSTAKA}

[1] Silitonga, T.D., 2019. PELAKSANAAN SISTEM INFORMASI MANAJEMEN RUMAH SAKIT (SIMRS) DI RUMAH SAKIT JIWA TAMPAN PROVINSI RIAU TAHUN 2017. Jurnal Kesehatan Komunitas, 5(3), pp.161-165.

[2] Mulyani, S., 2017. Sistem Informasi Manajemen Rumah Sakit: Analisis dan Perancangan. Abdi Sistematika.

[3] Handiwidjojo, W., 2015. Sistem informasi manajemen rumah sakit. Jurnal Eksplorasi Karya Sistem Informasi dan Sains, 2(2).

[4] Sari, M.M., Sanjaya, G.Y. and Meliala, A., 2016. Evaluasi sistem informasi manajemen rumah sakit (SIMRS) dengan kerangka HOT-FIT. SESINDO 2016, 2016.

[5] Hariana, E., Sanjaya, G.Y., Rahmanti, A.R., Murtiningsih, B. and Nugroho, E., 2013. Penggunaan sistem Informasi manajemen rumah sakit (SIMRS) di DIY. SESINDO 2013, 2013. 